\title{
ВMJ Global Health Thirty-year trends in the prevalence and severity of female genital mutilation: a comparison of 22 countries
}

\author{
Alissa Koski, Jody Heymann
}

To cite: Koski A, Heymann J. Thirty-year trends in the prevalence and severity of female genital mutilation: a comparison of 22 countries. BMJ Glob Health 2017;2:e000467. doi:10.1136/ bmjgh-2017-000467

Handling editor Seye Abimbola

- Additional material is published online only. To view please visit the journal online (http://dx.doi.org/10.1136/ bmjgh-2017-000467).

Received 10 July 2017 Revised 18 August 2017 Accepted 6 September 2017
Check for updates

WORLD Policy Analysis Center, UCLA Fielding School of Public Health, Los Angeles, California, USA

Correspondence to Dr. Alissa Koski; akoski@ph.ucla.edu

\section{ABSTRACT}

Introduction Female genital mutilation (FGM) harms women's health and well-being and is widely considered a violation of human rights. The United Nations has called for elimination of the practice by 2030 .

Methods We used household survey data to measure trends in the prevalence of FGM in 22 countries. We also examined trends in the severity of the practice by measuring changes in the prevalence of flesh removal, infibulation and symbolic 'nicking' of the genitals. We evaluated the extent to which measurement error may have influenced our estimates by observing the consistency of reports for the same birth cohorts over successive survey waves.

Results The prevalence of all types of FGM fell in 17 of 22 countries we examined. The vast majority of women who undergo FGM have flesh removed from their genitals, likely corresponding to the partial or total removal of the clitoris and labia. Infibulation is still practised throughout much of sub-Saharan Africa. Its prevalence has declined in most countries, but in Chad, Mali and Sierra Leone the prevalence has increased by $2-8$ percentage points over 30 years. Symbolic nicking of the genitals is relatively rare but becoming more common in Burkina Faso, Chad, Guinea and Mali.

Conclusion FGM is becoming less common over time, but it remains a pervasive practice in some countries: more than half of women in 7 of the 22 countries we examined still experience FGM. The severity of the procedures has not changed substantially over time. Rigorous evaluation of interventions aimed at eliminating or reducing the harms associated with the practice is needed.

\section{INTRODUCTION}

Female genital mutilation (FGM), also known as female genital cutting or female circumcision, threatens the health and well-being of millions of girls, women and their children across the globe. The United Nations Sustainable Development Goals call for the elimination of the practice by $2030 .^{1}$

FGM refers to the partial or total removal of the external female genitalia or other injury to the female genital organs for non-therapeutic reasons. The WHO recognises four distinct types of the practice that range in

\section{Key questions}

What is already known about this topic?

- A small number of earlier studies have measured trends in the overall prevalence of self-reported female genital mutilation (FGM) across countries, but little attention has been paid to trends in the severity of the practice.

- The types of cutting being performed may have shifted in response to harm reduction proposals that encourage the substitution of severe forms with symbolic measures, such as 'nicking' of the genitals.

What are the new findings?

- We measured trends in the prevalence of the removal of flesh from the genitals, infibulation and symbolic 'nicking' of the genitals, which roughly correspond to the types of FGM defined by the WHO.

- We show that the vast majority of women who have undergone FGM have had flesh removed from their genitals, likely the partial or complete removal of the clitoris and labia.

- We found little evidence of a broad shift towards less extensive forms of FGM, although it appears that a small proportion of procedures are being substituted with symbolic nicking of the genitals in a handful of countries including Burkina Faso, Chad, Guinea and Mali.

\section{Recommendations for policy}

- The prevalence of FGM is declining slowly but steadily in 17 of the 22 countries we studied, but it remains a pervasive practice in many.

- There is limited indication that harm reduction efforts have yet resulted in substantial declines in the severity of the procedures performed on a national scale.

- Rigorous studies of the impact of interventions to eliminate or more effectively reduce the harms associated with FGM are needed.

severity from injuries to the genitalia that do not involve the removal of flesh, such as pricking, piercing or scraping (type 4), to infibulation, in which the vaginal opening is narrowed by cutting and reposition the labia to create a partial cover and may involve stitching the tissues together (type 3). Types 
1 and 2, also referred to as clitoridectomy and excision, respectively, involve the partial or complete removal of the clitoris and labia. ${ }^{2}$

FGM is widely practised in some regions of Africa and the Middle East. Motivations for the practice vary but are often tied to social mores that govern the expression of female sexuality. The practice is believed to reduce women's desire for sex and therefore limit the likelihood of premarital or extramarital sexual activity. ${ }^{3}$ It may also be considered a marker of group identity that symbolises a girl's transition to adulthood. There is strong social pressure to continue the practice among societies that believe cutting is necessary for group identity and marriageability. ${ }^{4}$

\section{Health consequences}

All types of FGM are potentially harmful. Immediate complications including bleeding, swelling, urine retention and pain are associated with all types of FGM, regardless of severity. ${ }^{5}$ In the longer term, women who have undergone FGM are at greater risk of adverse obstetric outcomes, including caesarean section and postpartum haemorrhage. Infants born to mothers who have undergone FGM are more likely to require resuscitation immediately following birth and have higher rates of stillbirth and neonatal mortality. ${ }^{6}$ The magnitude of both short-term and long-term risks appears to increase with the severity of the cutting performed. FGM can have a profound impact on women's sexual well-being. Two recent systematic reviews concluded that women who have undergone FGM experience reduced sexual desire and satisfaction and are more likely to experience dyspareunia (painful sexual intercourse). ${ }^{57}$ These practices may negatively affect women's mental health as well. Three studies suggest that women who have been cut may have elevated rates of post-traumatic stress, anxiety and other mental health disorders. ${ }^{8-10}$

Harm reduction approaches to FGM have been proposed in light of slow progress towards reducing the incidence of the procedure and continuing high levels of social support for the practice in some countries. The substitution of more extensive forms of FGM with less severe forms, such as nicking the clitoris, may mitigate the severity of long-term and short-term complications. ${ }^{611}$ Medicalising FGM by providing sterile blades or permitting healthcare providers to perform the procedure may also reduce the harms associated with it. ${ }^{12} 13$ However, these approaches have generated controversy. Some argue that they legitimise a practice that is widely considered a violation of human rights and that allowing healthcare providers to be involved constitutes a violation of medical ethics. ${ }^{13}$

Measuring trends in the overall prevalence of FGM is necessary to monitor progress towards the Sustainable Development Goals and to evaluate efforts to eliminate the practice in all forms. It is also important to understand whether the types of FGM being practised are shifting over time as this may affect the health burden associated with the procedures and will facilitate evaluation of harm reduction techniques. Earlier work measured changes in the proportion of women who reported undergoing any degree of cutting but paid little attention to trends in the types of FGM reported. ${ }^{14}{ }^{15}$ In this analysis, we used all available Demographic and Health Surveys (DHS) data to measure trends in the overall prevalence of FGM and in the severity of the procedures over a 30 -year period across 22 countries.

\section{DATA AND STATISTICAL METHODS}

The DHS collects internationally comparable information on FGM that permits examination of the prevalence and severity of the practice across countries. Women between 15 and 49 years of age are first asked whether they know of FGM. Those who are familiar are then asked if they have been cut themselves. Women who indicate that they have been cut are asked whether any flesh was removed from their genitals as part of the procedure and, if so, whether their genital area was sewn closed. Those who report that no flesh was removed are asked whether their genitals were 'nicked' without flesh removal. These questions permit a rough distinction between the types of FGM recognised by the WHO. Women who reported that flesh was removed from their genitals likely experienced clitoridectomy or excision (type 1 or 2). Those whose genitals were sewn likely underwent infibulation (type 3). Women who reported that they were cut but no flesh was removed or that their genitals were 'nicked' likely experienced type 4 .

We obtained DHS data from 22 countries that had included questions on FGM in at least one survey since 1990 and whose data were publicly available. Twenty of these countries are located in sub-Saharan African and two in the Middle East. We pooled data from all of the available surveys within each country, as listed in table 1 . Although data from each DHS wave are cross-sectional, they include respondents from a wide range of birth cohorts, which permits the measurement of trends over time. We limited our sample to women born between 1965 and 2000 and examined trends over 3-year birth cohorts in each country.

We examined five measures of FGM: the prevalence of all forms of cutting, forms that involve flesh removal, infibulation and 'nicking'. We found that in some countries a substantial proportion of women reported that they did not know whether flesh had been removed from their genitals and so we also measured trends in the prevalence of 'don't know' responses. We assumed women who reported that they had not heard of FGM had not been cut to any extent.

We estimated trends in the prevalence of these outcomes by calculating the predicted (marginal) probability of each outcome over birth cohorts using logistic regression. Within each country, we regressed dummy variables for each birth cohort on a binary indicator of each outcome and then used the coefficients associated 


\begin{tabular}{|c|c|c|}
\hline Country & DHS years used & Sample size \\
\hline \multicolumn{3}{|l|}{ Western Africa } \\
\hline Benin & 2001, 2006, 2011 & 36628 \\
\hline Burkina Faso & $1998,2003,2010$ & 29642 \\
\hline Cote d'Ivoire & 1998,2011 & 11990 \\
\hline Gambia & 2013 & 9979 \\
\hline Ghana & 2003 & 4469 \\
\hline Guinea & 1999, 2005, 2012 & 20083 \\
\hline Mali & 1995, 2001, 2006, 2012 & 38464 \\
\hline Niger & 1998, 2006, 2012 & 24224 \\
\hline Nigeria* & 2008, 2013 & 66863 \\
\hline Senegal & 2005, 2010, 2014, 2015 & 44856 \\
\hline Sierra Leone & 2008, 2013 & 22251 \\
\hline Togo & 2013 & 9002 \\
\hline \multicolumn{3}{|l|}{ Eastern Africa } \\
\hline Ethiopia & 2000,2005 & 22271 \\
\hline Kenya & 1998, 2003, 2008, 2014 & 33313 \\
\hline Tanzania & 1996, 2004, 2009, 2015 & 36602 \\
\hline Uganda & 2006, 2011 & 14989 \\
\hline \multicolumn{3}{|c|}{ Central and Southern Africa } \\
\hline Cameroon & 2004 & 4422 \\
\hline $\begin{array}{l}\text { Central African } \\
\text { Republic }\end{array}$ & 1994 & 3432 \\
\hline Chad & 2004, 2014 & 16542 \\
\hline Swaziland & 2006 & 4330 \\
\hline \multicolumn{3}{|l|}{ Middle East } \\
\hline Egypt & $\begin{array}{l}1995,2000,2005,2008 \\
2014\end{array}$ & 64396 \\
\hline Yemen & 2013 & 23953 \\
\hline
\end{tabular}

*Nigeria also collected data on FGM in the 2003 DHS, but the distribution of the sample in that year differs from that in more recent surveys, leading to significantly different estimates of the prevalence of FGM. ${ }^{14}$ We used the two most recent surveys. DHS, Demographic and Health Surveys; FGM, female genital mutilation.

with the dummy variables to predict the probability of each outcome in each birth cohort. We graphed our estimates over birth cohorts between 1965-1967 and 1995-1997, which allowed us to observe trends over the same time period in all of the countries studied, unlike earlier work which presented trends over survey years that differed across countries. We were able to obtain prevalence estimates for each birth cohort in countries that conducted surveys at approximately 5 -year intervals through recent history, but were more restricted in countries that fielded surveys at irregular intervals or that had not conducted one recently. In a few countries, we were able to obtain an estimate for the 1998-2000 cohort as well. All of the individual birth years within each 3-year cohort are represented by at least 50 women in order to ensure that our estimates are reasonably representative of the entire 3-year cohort. We quantified the magnitude of change in each of the outcomes over time by subtracting the prevalence among women born in 1965-1967 from that among women born in the most recent cohort for which data were available. All estimates are weighted using denormalised sampling weights following guidelines for the use of pooled data included in the DHS Sampling and Household Listing Manual. ${ }^{16}$

All of our outcomes are self-reported. Ongoing legislative and programmatic efforts to eliminate FGM may influence women's reporting behaviour and could lead to biased trend estimates. In countries that have banned the practice, women may be hesitant to report their status or the severity of the procedure. For example, women in northern Ghana who were interviewed about their FGM status in 1995 and again in 2000 gave inconsistent reports: $13 \%$ of women who reported they had been cut in 1995 reported that they had not been 5 years later after the country outlawed the practice. ${ }^{17}$ We looked for evidence of systematic reporting bias in six countries in which the prevalence of all forms of FGM had declined by 15 percentage points or more over a 30 -year period. To do this, we compared prevalence estimates for the same birth cohorts obtained from successive surveys using the method described above. If bias affected our estimates, we would expect to see inconsistent measures of prevalence across survey waves, with lower estimates among more recent surveys.

\section{RESULTS \\ All forms of cutting}

The proportion of women who experienced any type of genital cutting has fallen over time in almost all of the countries we examined, but it remains a pervasive problem in many of them (figures $1-4$, table 2). Despite small declines, the practice is still nearly universal in Guinea, Mali and Egypt, where $90 \%$ or more of women born between 1995 and 1997 reported undergoing some form of the procedure. More than half of women continue to be cut in Burkina Faso, Sierra Leone and the Gambia, where rates of cutting have not changed in 30 years (table 2). In contrast, fewer than $5 \%$ of women born in the most recent cohort reported being cut in Benin, Niger, Tanzania, Togo and Uganda.

\section{Flesh removal and uncertainty}

The vast majority of women who have undergone FGM have experienced substantial injury to the genital area. Nearly all women who reported undergoing the procedure had flesh removed from their genitals, corresponding to FGM types 1-3, which involve the partial or complete removal of the clitoris and labia. 'Nicking' of the genitals remains relatively rare in all of the countries we examined. We found this symbolic form of the practice most common in Burkina Faso, Chad and Guinea, 


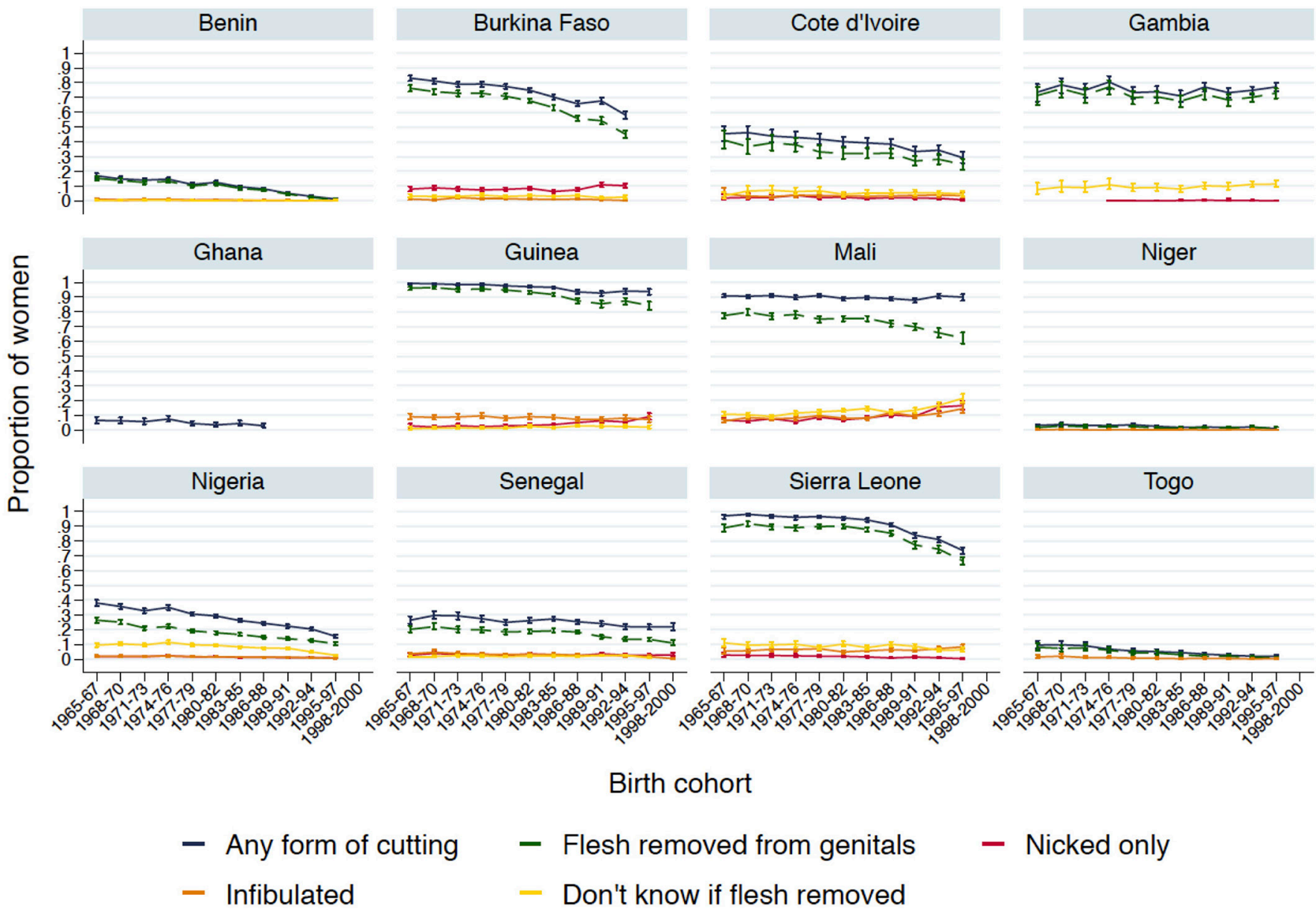

Figure 1 Trends in the prevalence and severity of female genital mutilation in Western African countries.

where between $9 \%$ and $16 \%$ of women born between 1992 and 1997 reported experiencing this form of FGM.

Observed trends in flesh removal and symbolic cutting in Burkina Faso, Mali and Chad suggest a slight shift towards less severe forms of the practice. In Mali, the proportion of women who report having undergone any form of FGM has remained stable over this period, but the prevalence of flesh removal has declined while nicking has increased. However, in most countries the discrepancy between the proportion of women who have been cut to any degree and the proportion who have had flesh removed from their genitals is more likely explained by a lack of knowledge of the extent of the procedure. In Cote d'Ivoire and Sierra Leone, approximately $5 \%$ of women born between 1995 and 1997 reported that they had been cut but did not know whether flesh had been removed from their genitals. In Gambia, more than $10 \%$ of women reported they did not know, and in Mali more than 20\% did not know (figures 1-4). This is unsurprising given that many girls are cut at a very young age.

\section{Infibulation}

Infibulation continues to be practised throughout much of sub-Saharan Africa. Between $7 \%$ and $15 \%$ of all women born between 1995 and 1997 in Guinea, Mali and Sierra Leone reported that their genital area was sewn. The rate of infibulation in Guinea has changed very little, if at all, over this 30-year period, but rates are rising in Mali and Sierra Leone (table 2). The prevalence of all women who report that their genitals were sewn has increased from $6 \%$ to $15 \%$ in Mali and from $6 \%$ to $8 \%$ in Sierra Leone (figure 1 and table 2). Fewer than 5\% of all women born in the most recent cohort in all of the other countries report that their genitals were sewed; in many cases the prevalence is less than $1 \%$.

We found little evidence to suggest that reporting bias influences our results. Prevalence estimates from successive DHS waves in Cote d'Ivoire, Kenya, Nigeria and Tanzania are remarkably consistent across birth cohorts (online supplementary figure 1). In Benin, estimates from the most recent survey wave are systematically lower than those from the oldest survey, which could indicate the presence of reporting bias. However, the same declining trend is illustrated across all of the survey waves. Estimates from the two surveys in Burkina Faso are nearly identical among older birth cohorts but diverge among more recent cohorts. The lower estimates come from the earlier survey though, which does not follow the pattern we would expect to see if women interviewed more recently are more reluctant to report their FGM status. This divergence could reflect the age at which girls are 


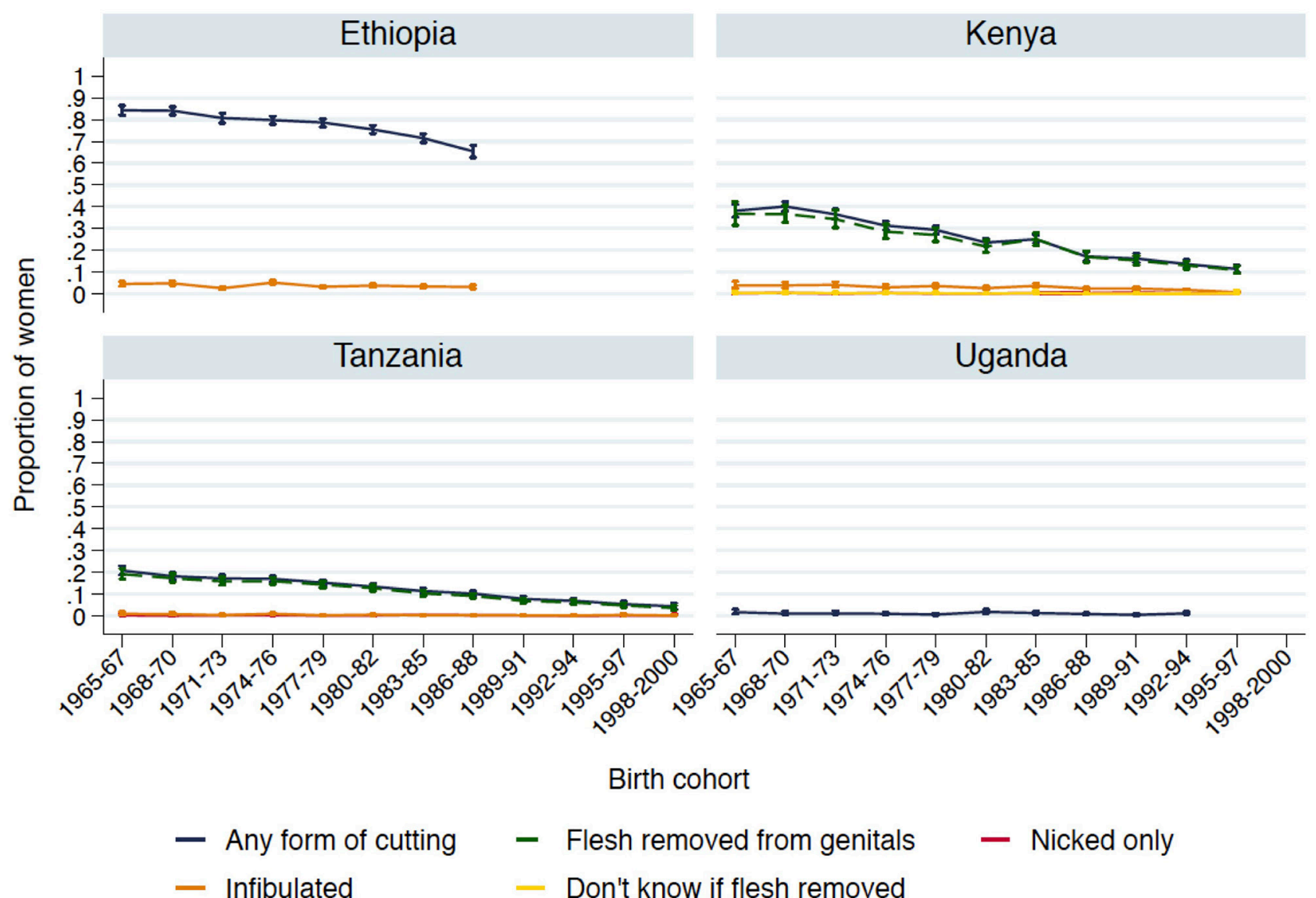

Figure 2 Trends in the prevalence and severity of female genital mutilation in Eastern African countries.

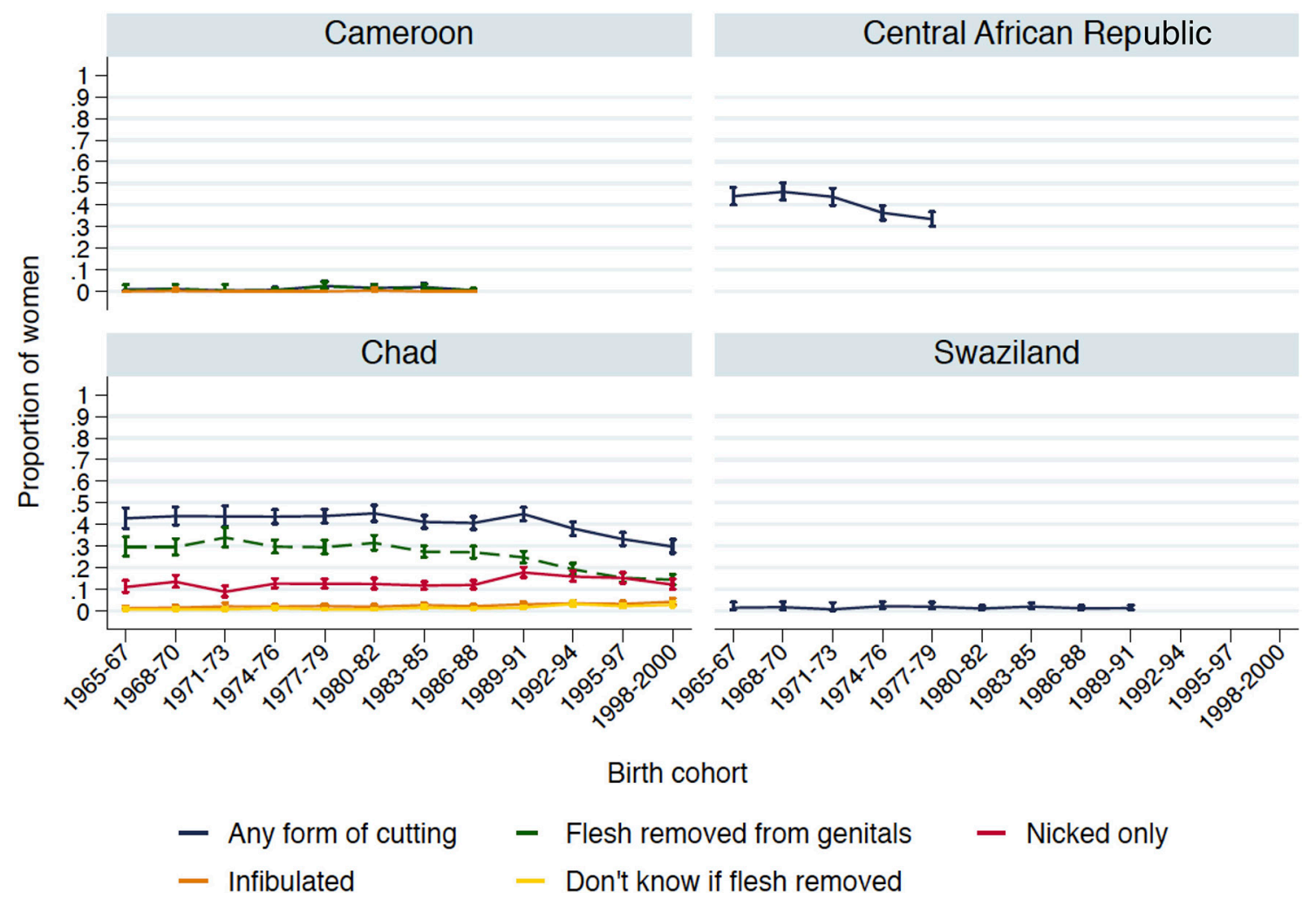

Figure 3 Trends in the prevalence and severity of female genital mutilation in Central and Southern African countries. 
cut in Sierra Leone. Girls born in the most recent cohort would have been interviewed when they were between 15 and 17 years of age. If some of them experienced FGM at a later age, we would expect to see an increase among the same birth cohort interviewed 5 years later.

\section{DISCUSSION}

The prevalence of FGM is falling in most of the countries that we assessed. The practice has been declining slowly and steadily for 30 years in many countries including Cote d'Ivoire, Nigeria, Ethiopia and Kenya, while reductions appear more recent in Chad and Sierra Leone. However, progress has not been uniform: the prevalence of FGM has remained high and stable in Mali and the Gambia for 30 years.

We found little evidence of a substantial shift in the severity of the procedures performed, although symbolic forms of FGM appear to be making small inroads in a handful of countries. The vast majority of women who are cut likely experience partial or total removal of the clitoris and labia, corresponding to WHO types 1 or 2 . Infibulation continues to be practised in many countries and rates may be rising in Mali and Sierra Leone. These are serious injuries that hinder women's health and sexual functioning throughout their lives. Estimates of flesh removal should be treated as lower bounds given the substantial proportion of women who reported that they did not know whether flesh had been removed from their genitals.

Our estimates assume that women correctly report their FGM status and are aware of the extent of their injuries. Validation studies have been conducted in clinical settings but may capture highly selected samples in countries where healthcare is not equally accessible across all population groups. However, validation studies outside of clinical settings would be ethically challenging to conduct as they would require the direct examination of women's genitalia, and are therefore unlikely to be pursued. One study conducted in Sudan compared women's self-reports of the extent of their cutting with classification based on clinical exams and found that as many as $25 \%$ of women did not accurately report the type of FGM they had experienced. ${ }^{18}$ The women were slightly more likely to under-report the extent of the injuries. A tendency to under-report FGM status was also found in Tanzania, providing further support for treating estimates of flesh removal and infibulation as lower bounds. ${ }^{19}$ The vast majority of women in a Nigerian study accurately reported their FGM status. ${ }^{20}$

The specific drivers of the decline in FGM are uncertain. Despite decades of efforts to stem the practice, there is very little high-quality evidence on the types of interventions that may be effective at preventing it. Many countries have instituted bans on FGM, but such policies may be difficult to enforce where the practice continues to have wide social support. ${ }^{21}$ This appears to be the case in Egypt, where multiple attempts to ban the practice have resulted in little progress towards reducing its prevalence. ${ }^{22}$ Aside from legislative efforts, a wide variety of programmes that encourage communities to abandon FGM traditions have been fielded. Unfortunately, few have been evaluated. A 2006 report by the Population Reference Bureau catalogued 92 projects aimed at abandoning FGM in 19 countries. Only four

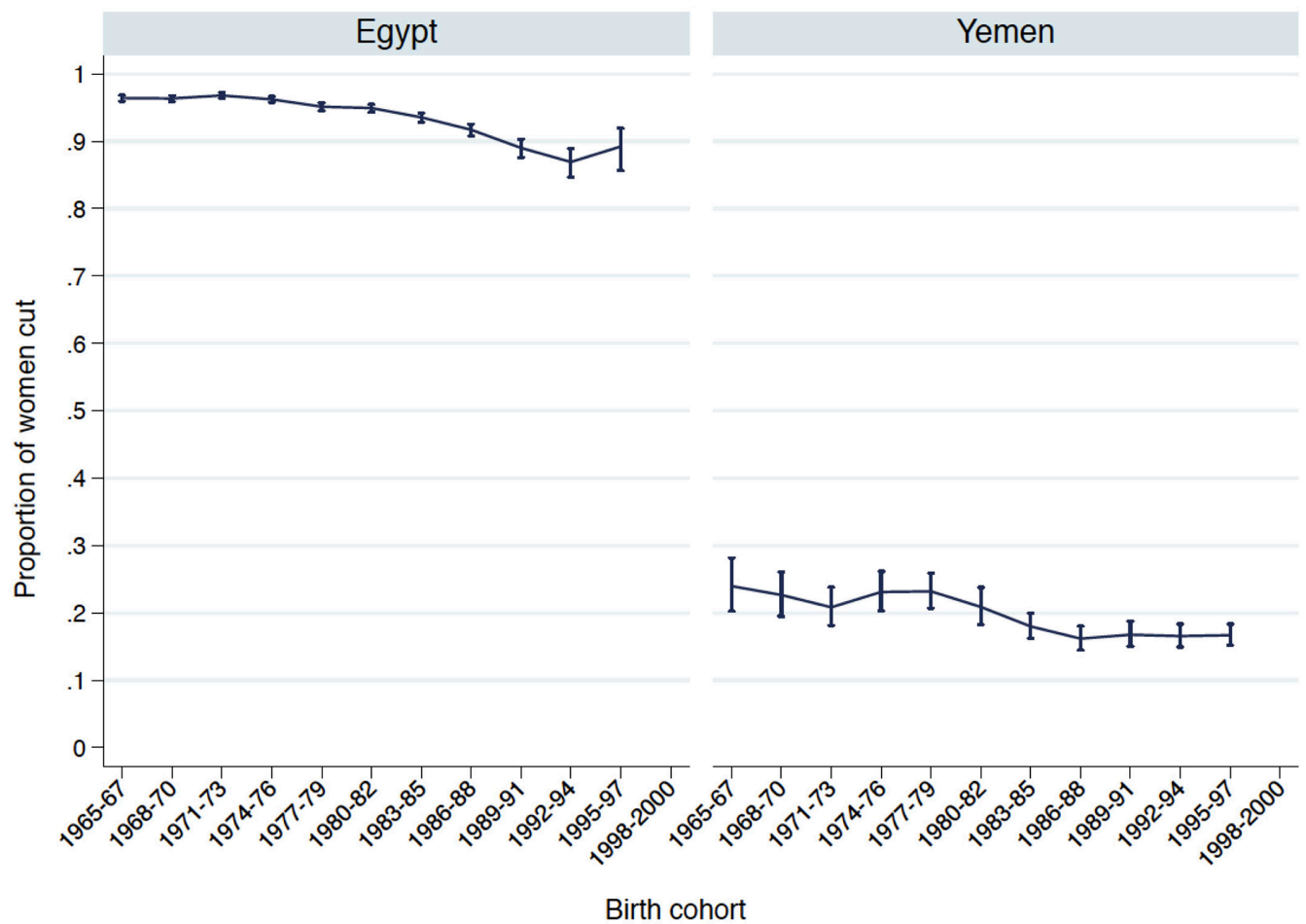

Figure 4 Trends in the prevalence of female genital mutilation in Egypt and Yemen. 
Table 2 Changes in the prevalence of various forms of FGM over birth cohorts

\begin{tabular}{|c|c|c|c|c|c|}
\hline Country & Cohort comparison & $\begin{array}{l}\text { All types of FGM } \\
\text { PD }(95 \% \mathrm{Cl})\end{array}$ & $\begin{array}{l}\text { Flesh removal } \\
\text { PD }(95 \% \mathrm{Cl})\end{array}$ & $\begin{array}{l}\text { Symbolic 'nick' } \\
\text { PD ( } 95 \% \mathrm{Cl})\end{array}$ & $\begin{array}{l}\text { Infibulation } \\
\text { PD (95\% Cl) }\end{array}$ \\
\hline \multicolumn{6}{|l|}{ Western Africa } \\
\hline Benin & 65-67 vs 95-97 & $-15.7(-17.5$ to -14.0$)$ & $-14.5(-16.1$ to -12.8$)$ & - & $-1.1(-1.6$ to -0.6$)$ \\
\hline Burkina Faso & $65-67$ vs $92-94$ & $-24.8(-27.8$ to -21.8$)$ & $-31.0(-34.2$ to -27.8$)$ & $2.3(0.1$ to 4.5$)$ & $-0.9(-1.6$ to -0.3$)$ \\
\hline Cote d'Ivoire & 65-67 vs 95-97 & $-16.2(-22.5$ to -9.9$)$ & $-16.5(-23.7$ to -9.4$)$ & $-1.2(-3.0$ to 0.5$)$ & $-1.0(-4.5$ to 2.4$)$ \\
\hline Gambia & 65-67 vs 95-97 & $3.6(-2.9$ to 10.0$)$ & $1.5(-5.5$ to 8.5$)$ & - & - \\
\hline Ghana & 65-67 vs 86-88 & $-3.6(-6.2$ to -1.1$)$ & - & - & - \\
\hline Guinea & 65-67 vs 95-97 & $-5.5(-7.4$ to -3.5$)$ & $-11.8(-14.7$ to -8.9$)$ & 6.3 (3.8 to 8.7 ) & $-1.9(-4.5$ to 0.8$)$ \\
\hline Mali & 65-67 vs 95-97 & $-0.9(-3.3$ to 1.5$)$ & $-15.1(-19.3$ to -10.8$)$ & $9.9(6.7$ to 13.0$)$ & 8.5 (5.2 to 11.7$)$ \\
\hline Niger & $65-67$ vs 95-97 & $-2.2(-3.3$ to -1.1$)$ & $-0.8(-1.8$ to 0.2$)$ & - & - \\
\hline Nigeria & 65-67 vs 95-97 & $-22.6(-24.9$ to -20.2$)$ & $-16.0(-18.2$ to -13.9$)$ & $-0.9(-1.6$ to -0.02$)$ & $-1.4(-2.0$ to -0.7$)$ \\
\hline Senegal & 65-67 vs 95-97 & $-4.6(-7.6$ to -1.6$)$ & $-6.8(-9.3$ to 4.3$)$ & $0.0(-1.3$ to 1.3$)$ & $-1.9(-3.2$ to -0.7$)$ \\
\hline Sierra Leone & 65-67 vs 95-97 & $-23.3(-25.9$ to -20.7$)$ & $-22.2(-25.7$ to -18.7$)$ & $-2.5(-4.0$ to -1.0$)$ & $2.8(0.3$ to 5.3$)$ \\
\hline Togo & 65-67 vs 95-97 & $-7.5(-10.3$ to -4.8$)$ & $-7.0(-9.6$ to -4.5$)$ & - & $-1.2(-2.2$ to -0.1$)$ \\
\hline \multicolumn{6}{|l|}{ Eastern Africa } \\
\hline Ethiopia & $65-67$ vs $86-88$ & $-18.9(-22.4$ to -15.3$)$ & - & - & $-1.4(-2.6$ to -0.01$)$ \\
\hline Kenya & 65-67 vs 95-97 & $-26.7(-30.1$ to -23.2$)$ & $-25.7(-31.5$ to -20.0$)$ & $-0.2(-0.5$ to 0.2$)$ & $-3.2(-4.8$ to -1.6$)$ \\
\hline Tanzania & 65-67 vs 95-97 & $-15.4(-17.7$ to -13.1$)$ & $-14.4(-17.1$ to -11.7$)$ & $-0.1(-0.5$ to 0.2$)$ & $-0.5(-1.3$ to 0.3$)$ \\
\hline Uganda & 65-67 vs 92-94 & $-0.5(-1.8$ to 0.7$)$ & - & - & - \\
\hline \multicolumn{6}{|c|}{ Central and Southern Africa } \\
\hline Cameroon & $65-67$ vs $86-88$ & $-0.5(-1.8$ to 0.8$)$ & $0.1(-0.9$ to 1.1$)$ & - & - \\
\hline $\begin{array}{l}\text { Central African } \\
\text { Republic }\end{array}$ & $65-67$ vs $77-79$ & $-10.6(-15.9$ to -5.3$)$ & - & - & - \\
\hline Chad & 65-67 vs 95-97 & $-9.6(-15.2$ to -4.0$)$ & $-14.3(-19.3$ to -9.3$)$ & $4.2(0.4$ to 7.9$)$ & $2.0(0.6$ to 3.3$)$ \\
\hline Swaziland & $65-67$ vs $89-91$ & $-0.2(-1.9$ to 1.5$)$ & - & - & - \\
\hline \multicolumn{6}{|l|}{ Middle East } \\
\hline Egypt & $65-67$ vs $95-97$ & $-7.2(-10.3$ to -4.0$)$ & - & - & - \\
\hline Yemen & 65-67 vs 95-97 & $-7.3(-11.5$ to -3.0$)$ & - & - & - \\
\hline
\end{tabular}

FGM, female genital mutilation; PD, prevalence difference.

had been evaluated using controlled before-and-after designs. $^{23}$ A more recent systematic review identified a total of eight impact evaluation studies conducted in sub-Saharan Africa. ${ }^{24}$ Of these, only two measured the effect of interventions on the prevalence of FGM. Both studies measured the effect of community-based educational programmes for adults and reported a reduction in the number of young girls who had been cut. ${ }^{24}{ }^{25}$ Population-level improvements in educational attainment and increasing urbanisation may also contribute to changing attitudes towards these practices, although these relationships may vary across and within countries. Further investigation is warranted to better understand what works to prevent FGM and how to mitigate the harms associated with it.

We present national-level estimates of the prevalence of FGM in 22 countries but recognise that both prevalence and trends vary substantially across subgroups within many countries. In some, it is practised primarily within certain ethnic groups. Estimates may also differ according to educational attainment, religious identity or area of residence. ${ }^{14} \mathrm{~A}$ full examination of trends among each of these categories in every country was beyond the scope of this analysis but may assist in the targeting of programmes related to FGM. Research is also needed to understand the extent of FGM in countries that have not collected nationally representative data on the topic. There is evidence of FGM customs in Indonesia, Malaysia and India, among others. ${ }^{26-28}$ Immigrant communities may also continue FGM in countries where it has not been traditionally practised. For example, two recent criminal prosecutions have drawn attention to the practice within the USA. ${ }^{29} 30$

Slow progress is being made toward reducing the prevalence of FGM but the practice remains nearly universal in some countries, irreparably damaging the health and well-being of hundreds of millions of women. There is little high-quality evidence of what works to prevent girls from undergoing these procedures. Studies suggest that community-based educational interventions may shift 
attitudes toward the practice, but it remains unclear whether changes in attitudes translate into reductions in FGM or whether such programmes could be scaled up to affect change on a national level. Well-planned and documented interventions and rigorous evaluations are necessary to advance efforts to curtail FGM and the harms associated with it, especially as the 2030 deadline for the Sustainable Development Goals draws nearer.

Contributors AK conceived of the study, conducted all analyses and wrote the first draft of the manuscript. JH contributed to the design of the study and revised the manuscript for important intellectual content.

Funding The Conrad N Hilton Foundation (grant no: 20150167) provided funding for AK through a grant focused on the United Nations Sustainable Development Goals. The funding organisation had no role in the design of the research, the collection, analysis or interpretation of data, the writing of the report, or the decision to submit the work for publication.

Competing interests None declared.

Provenance and peer review Not commissioned; externally peer reviewed.

Data sharing statement All data used in this analysis are publicly available from the DHS Program.

Open access This is an open access article distributed in accordance with the Creative Commons Attribution Non Commercial (CC BY-NC 4.0) license, which permits others to distribute, remix, adapt, build upon this work non-commercially, and license their derivative works on different terms, provided the original work is properly cited and the use is non-commercial. See: http://creativecommons.org/ licenses/by-nc/4.0/

(C) Article author(s) (or their employer(s) unless otherwise stated in the text of the article) 2017. All rights reserved. No commercial use is permitted unless otherwise expressly granted.

\section{REFERENCES}

1. United Nations. Sustainable development goal 5: achieve gender equality and empower all women and girls [internet]. https://sustaina bledevelopment.un.org/sdg5 (accessed 20 Jun 2017).

2. World Health Organization. Female genital mutilation: report of a WHO technical working group [internet]. Geneva: World Health Organization, 1996:1-32. Report No: WHO/FRH/WHD/96.10. http:// apps.who.int/iris/bitstream/10665/63602/1/WHO_FRH_WHD_96.10. pdf

3. Cook RJ, Dickens BM, Fathalla MF. Female genital cutting (mutilation/circumcision): ethical and legal dimensions. Int $\mathrm{J}$ Gynaecol Obstet 2002;79:281-7.

4. Gage AJ, Van Rossem R. Attitudes toward the discontinuation of female genital cutting among men and women in Guinea. Int $J$ Gynaecol Obstet 2006;92:92-6.

5. Berg RC, Underland V, Odgaard-Jensen J, et al. Effects of female genital cutting on physical health outcomes: a systematic review and meta-analysis. BMJ Open 2014;4:e006316.

6. Banks E, Meirik O, Farley T, et al. Female genital mutilation and obstetric outcome: WHO collaborative prospective study in six African countries. Lancet 2006;367:1835-41.

7. Berg RC, Denison E. Does Female Genital Mutilation/Cutting (FGM/C) affect women's sexual functioning? A systematic review of the sexual consequences of FGM/C. Sex Res Social Policy 2012:9:41-56.

8. Behrendt A, Moritz S. Posttraumatic stress disorder and memory problems after female genital mutilation. Am J Psychiatry 2005;162:1000-2.
9. Kizilhan JI. Impact of psychological disorders after female genital mutilation among Kurdish girls in Northern Iraq. Eur J Psychiat 2011;25:92-100.

10. Knipscheer J, Vloeberghs E, van $\operatorname{der}$ Kwaak A, et al. Mental health problems associated with female genital mutilation. BJPsych Bull 2015;39:273-7.

11. Arora KS, Jacobs AJ. Female genital alteration: a compromise solution. J Med Ethics 2016;42:148-54.

12. Shell-Duncan B. The medicalization of female 'circumcision': harm reduction or promotion of a dangerous practice? Soc Sci Med 2001;52:1013-28.

13. Pearce AJ, Bewley S. Medicalization of female genital mutilation. Harm reduction or unethical? Obstet Gynaecol Reprod Med 2014;24:29-30

14. Yoder PS, Wang S. Female genital cutting: the interpretation of recent DHS data. Calverton, Maryland: ICF International, 2013. Report No: DHS Comparative Reports 33.

15. Yoder PS, Wang S, Johansen E. Estimates of female genital mutilation/cutting in 27 African countries and Yemen. Stud Fam Plann 2013;44:189-204.

16. ICF International. Demographic and health survey sampling and household listing manual. Calverton, Maryland: MEASURE DHS, 2012:109.

17. Jackson EF, Akweongo P, Sakeah E, et al. Inconsistent reporting of female genital cutting status in northern Ghana: explanatory factors and analytical consequences. Stud Fam Plann 2003;34:200-10.

18. Elmusharaf S, Elhadi N, Almroth L. Reliability of self reported form of female genital mutilation and WHO classification: cross sectional study. BMJ 2006;333:124.

19. Klouman E, Manongi R, Klepp KI. Self-reported and observed female genital cutting in rural Tanzania: associated demographic factors, HIV and sexually transmitted infections. Trop Med Int Health 2005;10:105-15.

20. Snow RC, Slanger TE, Okonofua FE, et al. Female genital cutting in southern urban and peri-urban Nigeria: self-reported validity, social determinants and secular decline. Trop Med Int Health 2002; 7:91-100.

21. United Nations. Female genital mutilation/cutting: a statistical overview and exploration of the dynamics of change. UNICEF, 2013:1-194.

22. Hassanin IM, Shaaban OM. Impact of the complete ban on female genital cutting on the attitude of educated women from Upper Egypt toward the practice. Int J Gynaecol Obstet 2013;120:275-8.

23. Feldman-Jacobs C, Ryniak S. Abandoning female genital mutilation/ cutting: an in-depth look at promising Practices. Population Reference Bureau, 2006:1-74.

24. Berg RC, Denison E. Interventions to reduce the prevalence of female genital mutilation/cutting in African countries. International Initiative for Impact Evaluation, 2013:1-155. Report No: Systematic Review 009.

25. Diop NJ, Askew I. The effectiveness of a community-based education program on abandoning female genital mutilation/cutting in Senegal. Stud Fam Plann 2009;40:307-18.

26. Isa AR, Shuib R, Othman MS. The practice of female circumcision among Muslims in Kelantan, Malaysia. Reprod Health Matters 1999;7:137-44.

27. Budiharsana M, Amaliah L, Utomo B E. Female circumcision in Indonesia. Jakarta: Population Council, 2003:1-56.

28. Baweja $\mathrm{H}$, ed. India's dark secret [internet]. Hindustan Times. http:// www.hindustantimes.com/static/fgm-indias-dark-secret/ (accessed 20 Jun 2017)

29. Fortin J. Michigan doctor is accused of genital cutting of 2 girls. The New York Times [Internet], 2017:1-3. https://www.nytimes.com/ 2017/04/13/us/michigan-doctor-fgm-cutting.html

30. Victor D. Father imprisoned for genital cutting is deported to Ethiopia. The New York Times [Internet], 2017. https://www.nytimes. com/2017/03/14/us/father-imprisoned-for-genital-cutting-isdeported-to-ethiopia.html 